\title{
$\begin{array}{ll}\text { Research Square } & \text { Preprints are preliminary reports that have not undergone peer review. }\end{array}$ or referenced by the media as validated information. \\ Determinants of the Practice of Exclusive \\ Breastfeeding in Guinea: Evidence from 2018 Guinean Demographic and Health Survey
}

\section{Anne Marie Soumah}

Cellule de recherche en santé de la reproduction en Guinée

Mamadou Diouldé Baldé

Cellule de recherche en santé de la reproduction en Guinée

Mahamadi Tassembedo

Ministère de la santé

Ousmane OUEDRAOGO ( $\sim$ ouedou2@yahoo.fr)

Institut Africaine de Santé Publique

Franck Garanet

Institut de Recherche en Sciences de la Santé

Adja Mariam Ouédraogo

Institut de Recherche en Sciences de la Santé

Aminata Yara

Ministère de la santé

Mamady Koulibaly

Ministère de la santé

Ibrahima Camara

Ministère de la santé

Seni Kouanda

Institut Africaine de Santé Publique

\section{Research Article}

Keywords: Exclusive breastfeeding, Determinants, Guinea, Demographic and Health Survey

Posted Date: January 27th, 2021

DOI: https://doi.org/10.21203/rs.3.rs-140355/v1

License: (1) (1) This work is licensed under a Creative Commons Attribution 4.0 International License.

Read Full License 
Version of Record: A version of this preprint was published at BMC Nutrition on August 9th, 2021. See the published version at https://doi.org/10.1186/s40795-021-00450-2. 


\section{Abstract}

Background: Exclusive breastfeeding is recognized as one of the key interventions with proven effectiveness in reducing child morbidity and mortality and malnutrition. However, with the current trend in breastfeeding rates in Guinea, the World Health Assembly target of at least $50 \%$ by 2025 is likely to be compromised.

The objective of this study was to identify the individual and contextual determinants of the practice of Exclusive Breastfeeding in Guinea.

Method: We conducted a secondary analysis of data from the 2018 Guinea Demographic and Health Survey (DHS).

The study population consisted of women who gave birth between the ages of 15 and 49 . Our sample consisted of women who had their last birth six (06) months prior to collection. The enumeration areas were our second level. A multilevel logistic regression was performed using Stata version 15.1 software. Three statistical models were implemented: The final model was obtained using the bottom-up step-bystep method. The intra-class correlation coefficient was calculated.

Results: On the 851 women included in our study, $33 \%$ reported having exclusively breastfed during the first 6 months of life of their children. After a multivariate analysis, the variables associated with exclusive breastfeeding are : children aged 2-3 months $(\mathrm{OR}=0.53 \mathrm{Cl} 95 \%=[0.36-0.79])$ and children aged $4-5$ months $(\mathrm{OR}=0.23 \mathrm{IC} 95 \%=[0.14-0.36]$ and $p=0.0000)$, women in the Faranah area $(\mathrm{OR}=2.69 \mathrm{IC} 95 \%$ $=[1.21-5.94]$ and $p=0.014)$ and those in Mamou $(O R=2.27 \mathrm{IC} 95 \%=[1.00-5.94]$ and $p=0.049)$, women who gave birth in a health facility $(O R=1.94 \mathrm{IC} 95 \%=[1.34-2.80]$ and $p=0.0000)$ and women living in polygamous households $(\mathrm{OR}=0.68 \mathrm{IC} 95 \%=[0.48-0.98]$ and $\mathrm{p}=0.042)$.

Conclusion: The practice of exclusive breastfeeding remains low in Guinea. For the achievement of Sustainable Development Goals, particularly the improvement of exclusive breastfeeding practices, the individual and contextual determinants identified in this study should be taken into consideration in policies and programmes.

\section{Introduction}

Malnutrition is a real public health problem in developing countries. Every year, it is involved in nearly $45 \%$ of the 11 million deaths of children under five in these countries . [1]. Guinea, like other countries in subSaharan Africa, faces a worrying nutritional situation. According to the results of the latest Demographic and Health Survey (DHS) of $2018,30 \%$ of children under five are stunted or chronically malnourished and $13 \%$ are severely stunted. [2] . Exclusive breastfeeding is one of the recommended feeding practices to prevent this situation. The rate of exclusive breastfeeding was $28.3 \%$ according to the SMART national nutrition survey. [3]. At the current rate of progress in Guinea, the achievement of the targets set by the World Health Assembly of at least $50 \%$ by 2025 is likely to be compromised. [4]. 
Exclusive breastfeeding up to six months is one of the specific nutrition interventions proven effective in preventing chronic malnutrition according to the Lancet publications. [5, 6]. Exclusive breastfeeding reduces child Mortality rates by up to $13 \%$ in low income countries [7]. Optimal breastfeeding practices such as early initiation and exclusive breastfeeding are the key and easiest interventions for the reduction of infant morbidity and mortality. [8, 9].

Breastmilk confers short- and long-term benefits to both child and mother [10], improves the mother-child bond, enhances immunity and reduces the cost of buying artificial milk [11-14].

Globally, only $38 \%$ of infants $0-6$ months of age are exclusively breastfed [15]. In West and Central Africa $20 \%$ of children under the age of 6 months are exclusively breastfed [16].

Many efforts have been made to improve the health of children, including infant feeding [17]. These initiatives include the promotion of optimum infant and young child feeding practices (IYCF), the International Code of Marketing of Breast milk Substitutes (BMS), the Innocenti declaration, the BabyFriendly Hospitals initiative (BFHI), more recently, the 2025 global nutrition goals and the sustainable development goals [16]. Despite these efforts, the evolution of breastfeeding practices has been slow and disproportionate in Guinea especially, exclusive breastfeeding.

Hence the need to conduct contextual studies to better understand the determinants of the practice of exclusive breastfeeding in order to guide policies and programs in this area.

Previous studies conducted in several countries such as India, Nigeria and Ethiopia are unanimous on the association between the level of education of the mother, her age, the number of antenatal consultations, the type of assistance to childbirth, socioeconomic status, certain traditional beliefs, practices and rites and the practice of exclusive breastfeeding [18-20].In Guinea, the achievement of objective 2 of the Sustainable Development Goals (SDGs) as well as the targets of the World Health Assembly calls for a rethinking of the intervention strategies put in place, hence the need to identifies the determinants of the practice of exclusive breastfeeding. To our knowledge, no research has been conducted in this context, it therefore seemed necessary to us to conduct the present study in order to fill this scientific gap.

\section{Materials And Methods}

\section{Type of study}

This was a secondary analysis of data from the Guinea Demographic and Health Survey (DHS) conducted in 2018 which is a cross-sectional survey. The collection methodology as well as the reports are available and accessible on the DHS program website (http://dhsprogram.com). For this study, the data from the women's individual questionnaire were used. For this study, the data from the individual questionnaire of women were used in particular information on the nutritional practices of children, including breastfeeding.

\section{Study population and sampling}


We considered as the study population all women aged 15 to 49 from the individual woman questionnaire. The number of women surveyed was 10,506. Our analysis focused on women who had their last birth six (6 months) before the collection and who consented to the survey during the collection period.

This study included all mothers of children who had their last birth six months before the data collection, and whether or not they practiced exclusive breastfeeding; present during the visit of the investigators and who answered the question on breastfeeding. The following were not included in this study: Mothers whose children were not alive at the time of collection; those whose newborns did not live with them and mothers whose children are over 6 months of age (Figure 1).

\section{Study variables}

Our dependent variable was exclusive breastfeeding. This variable was obtained from a set of variables related to infant feeding.

First, we created the dichotomous variables that corresponded to the types of food that the mother gave the child the 24 hours preceding the survey.

Secondly, we grouped together all the variables whose modality is to have ingested a liquid or a solid other than breast milk. This variable constituted the modality "not having been exclusively breastfed for the variable exclusive breastfeeding. After the construction of the dependent variable, we proceeded to the following recoding:

All mothers who answered that they had not given their child any food other than breast milk were coded 1 and the modality which corresponds to the ingestion of foods other than breast milk for the child was coded 0 .

Variables at the individual level (level 1) were the individual characteristics of the mother and child: mother's age, education level, marital status, parity, region of residence, occupation of woman, type of household, number of antenatal consultations, place of delivery, type of delivery assistance, mode of delivery, household size, type of wealth quintile, the child's breastfeeding age and gender.

Community level variable (level 2) is represented by the enumeration area or community level. The contextual variable in our study is place of residence.

\section{Data analysis}

For the entire analysis, STATA 15.1 software was used. Before the analysis started, data cleaning, labeling, and recoding were done for all of the selected variables. The analysis was carried out in three stages.

The descriptive analysis of all the selected variables was the first step. The socio-demographic and maternal characteristics of the subjects studied were described. The percentages were calculated for 
each variable.

The univariate analysis consisted in measuring the association between the dependent variable and each of the independent variables selected by performing a simple logistic regression. A variable is retained for the construction of the multilevel model when its degree of significance $p$-value is less than $20 \%$.

For multivariate analysis, a binary multilevel logistic regression with random effect was performed using the ascending step-by-step method. The adjusted SDGs ratios were estimated with their p-value and their confidence interval. Successive models were compared using the likelihood ratio test. This involved multivariate hierarchical analysis to determine the fixed and random effects of the characteristics associated with the practice of exclusive breastfeeding. Using this same analytical technique, we looked for associations between the practice of Exclusive breastfeeding and variables at the individual and community level. Three two (2) level statistical models have been implemented:

The first model did not contain any independent variables. This allowed us to compare our multi-level regression model to a classic logistic model and to appreciate the variance of exclusive breastfeeding between the different EAs.

The second model was obtained after the introduction of the explanatory variables of the individual level.

The third model (3) or the complete model, which contains in addition to the variables of the individual level, the variable of the contextual level which is the place of residence.

The intra-class correlation coefficient was calculated for each statistical model and the discriminating power of the model was calculated using the Roc table.

\section{Ethical consideration}

This survey benefited from the approval of the Health Research Ethics Committee before its implementation. The database was obtained after a request to the EDS database management program (DHS-Program) which gave us its favorable opinion for the use of this database.

\section{Results}

\section{The basic characteristics of the sample}

A total of 851 women were included in the study. Mothers with children in the 25-34 age group were the most represented with $44.77 \%$ followed by the $15-24$ age group with $35.37 \%$. The $35-49$-year olds only represented $19.86 \%$. The majority $(75.79 \%)$ of women resided in rural areas and had no education (77.91\%). Almost all (96.83\%) of them were married. More than a quarter of them (27.38\%) lived in households considered to be poorer. While those who lived in very wealthy households were $11.99 \%$. Women who had a job at the time of the survey represented $61.57 \%$ of all mothers interviewed. Out of all 
the women in our sample, multiparous women were the most represented with $45.24 \%$, followed by pauciparous women with $36.48 \%$.

Table 1: Basic characteristics of the sample 


\begin{tabular}{|c|c|c|}
\hline Variables & Size (n) & Percentage (\%) \\
\hline \multicolumn{3}{|c|}{ Individual characteristicsMother } \\
\hline Mother's age & $(n=851)$ & \\
\hline 15 to 24 years & 301 & 35.37 \\
\hline 25 to 34 years & 381 & 44.70 \\
\hline 35 to 49 years & 169 & 19.86 \\
\hline Mother's education level & $(n=851)$ & \\
\hline None & 663 & 77.91 \\
\hline Primary & 91 & 10.69 \\
\hline Secondary/Higher & 97 & 11.40 \\
\hline Marital status & $(n=851)$ & \\
\hline Single & 27 & 3.17 \\
\hline Married/Free Union & 824 & 96.83 \\
\hline Region of residence & $(n=851)$ & \\
\hline Boké & 114 & 13.40 \\
\hline Conakry & 73 & 8.58 \\
\hline Faranah & 126 & 14.81 \\
\hline Kankan & 144 & 16.92 \\
\hline Kindia & 104 & 12.22 \\
\hline Labé & 101 & 11.87 \\
\hline Mamou & 92 & 10.81 \\
\hline Nzérékoré & 97 & 11.40 \\
\hline Parity & $(n=851)$ & \\
\hline Primipare & 138 & 16.22 \\
\hline Paucipares & 328 & 38.54 \\
\hline Multipare & 385 & 45.24 \\
\hline Mother's work & $(n=851)$ & \\
\hline No & 327 & 38.43 \\
\hline Yes & 524 & 61.57 \\
\hline
\end{tabular}




\begin{tabular}{|lll|}
\hline Type of home & $(\mathrm{n}=851)$ & \\
\hline Monogame & 503 & 61.49 \\
\hline Polygamous & 315 & 38.51 \\
\hline Antenatal consultation & $(\mathrm{n}=851)$ & \\
\hline No ANC & 110 & 13.22 \\
\hline One to three ANCs & 444 & 53.37 \\
\hline Four ANCs and more & 297 & 34.90 \\
\hline Place of delivery & $(\mathrm{n}=851)$ & \\
\hline At home & 419 & 49.24 \\
\hline In a health facility & 432 & 50.76 \\
\hline Mode of delivery & $(\mathrm{n}=849)$ & \\
\hline Base track & 825 & 97.17 \\
\hline Caesarean section & 24 & 2.83 \\
\hline Type of delivery & $(\mathrm{n}=851)$ & \\
\hline Unique & 833 & 97.88 \\
\hline Twins & $75=851)$ & \\
\hline Birth assistance & 18 & 2.12 \\
\hline unassisted childbirth & $(\mathrm{n}=851)$ & \\
\hline assisted childbirth & 776 & 91.19 \\
\hline Poverty quintile & $(\mathrm{n}=851)$ & \\
\hline Poorest & 399 & 46.89 \\
\hline Poor & 452 & 53.11 \\
\hline Medium rich & $(\mathrm{n}=851)$ & \\
\hline Rich & 233 & 27.38 \\
\hline Richer & 191 & 22.44 \\
\hline Religion & 169.86 \\
\hline Muslim & & \\
\hline Christian & & \\
\hline Ethnic group & & \\
\hline & & \\
\hline
\end{tabular}




\begin{tabular}{|lll|}
\hline Soussou & 155 & 18.21 \\
\hline Malinké & 340 & 39.95 \\
\hline Kissi & 272 & 31.96 \\
\hline Guerezé & 39 & 4.58 \\
\hline Autres & 36 & 4.23 \\
\hline Size of household & 9 & 1.06 \\
\hline 2 to 6 people & $(\mathrm{n}=851)$ & \\
\hline More than 6 people & 343 & 40.31 \\
\hline Age of the child & 508 & 59.69 \\
\hline 0 to 1 month & $(\mathrm{n}=851)$ & \\
\hline 2 to 3 months & 273 & 32.08 \\
\hline 4 to 5 months & 319 & 37.49 \\
\hline Gender of the child & 259 & 30.43 \\
\hline Male & $(\mathrm{n}=851)$ & \\
\hline Female & 422 & 49.59 \\
\hline CharacteristicsCommunity & 429 & 50.41 \\
\hline Place of residence & $(\mathrm{n}=851)$ \\
\hline Urban & 206 & 24.21 \\
\hline Rural & 645 & 75.79 \\
\hline
\end{tabular}

\section{Prevalence of exclusive breastfeeding in Guinea}

Our results show a prevalence of $33 \%(95 \% \mathrm{Cl}=[0.18-0.24])$.

\section{Multilevel analysis}

Table Il presents the result of the multilevel binary logistic regression model in the explanation of the practice of exclusive breastfeeding. After controlling for the other variables, the explanatory variables that were statistically associated with the practice of exclusive breastfeeding at the $5 \%$ threshold were the child's breastfeeding age, region of residence, place of childbirth and type of home. 
The age of breastfeeding was associated with exclusive breastfeeding in both univariate and multilevel analysis. After controlling for the other variables, children in the 2 to 3 month age group were $47 \%$ less likely to be exclusively breastfed by their mothers during the first 6 months of their life compared to children in the 0 to 1 month $(\mathrm{OR}=0.5395 \% \mathrm{Cl}=[0.36-0.79])$ with a statistically significant $\mathrm{p}$. Children in the 4 to 5 month age group had a 77\% reduced chance of being exclusively breastfed by their mothers compared to children in the 0 to 1 month age group $(\mathrm{OR}=0.2395 \% \mathrm{Cl}=[0.14-0.36]$ and $\mathrm{p}=0.0000)$.

Compared to women in the Conakry region, women in the Faranah region were 2.69 times more likely to exclusively breastfeed their children during the first six (06) months of life (OR $=2.6995 \% \mathrm{Cl}=[1.21-5.94]$ and $p=0.014)$. Also, Mamou women were 2.27 times more likely to practice exclusive breastfeeding in the first 6 months of their children's life $(\mathrm{OR}=2.2795 \% \mathrm{Cl}=[1.00-5.94]$ and $\mathrm{p}=0.049)$.

Women who had given birth in a health facility were $94 \%$ more likely to practice exclusive breastfeeding compared to those who gave birth at home $(\mathrm{OR}=1.9495 \% \mathrm{Cl}=[1.34-2.80]$ and $\mathrm{p}=0.0000)$.

Mothers of children living in polygamous households compared to those living in monogamous households had a $32 \%$ reduced chance of practicing exclusive breastfeeding $(\mathrm{OR}=0.6895 \% \mathrm{Cl}=[0.48-$ $0.98]$ and $p=0.042$ ).

In the empty model, the enumeration areas (EAs) explained $23 \%$ of the variance in the practice of exclusive breastfeeding. After inclusion of individual and contextual variables, this variance was reduced to $0.5 \%$. This suggests that part of the practice of exclusive breastfeeding is explained by contextual variables.

\section{Table 2: Multilevel Analysis}




\begin{tabular}{|c|c|c|c|c|c|c|}
\hline \multirow[t]{2}{*}{ Variable } & \multicolumn{2}{|c|}{ Empty model } & \multicolumn{2}{|l|}{ Model 1} & \multicolumn{2}{|l|}{ Model 2} \\
\hline & OR & IC & OR & IC & OR & IC \\
\hline \multicolumn{7}{|c|}{ Breastfeeding age of the child } \\
\hline 0 to 1 month & & & 1 & & 1 & \\
\hline 2 to 3 months & & & $0.53^{\star \star \star}$ & {$[0.36-0.79]$} & $0.53^{\star \star \star}$ & {$[0.36-0.79]$} \\
\hline 4 to 5 months & & & $0.22^{\star \star \star}$ & {$[0.14-0.36]$} & $0.23^{\star \star \star}$ & {$[0.14-0.36]$} \\
\hline \multicolumn{7}{|l|}{ Region } \\
\hline Conakry & & & 1 & & 1 & \\
\hline Boké & & & 0.70 & [0.29-1.67] & 0.72 & {$[0.30-1.62]$} \\
\hline Faranah & & & $2.67^{\star}$ & [1.18-6.03] & $2.69 *$ & {$[1.21-5.94]$} \\
\hline Kankan & & & 2.03 & {$[0.93-4.44]$} & 1.97 & {$[0.92-4.24]$} \\
\hline Kindia & & & 1.36 & [0.59-3.11] & 1.35 & {$[0.61-3.01]$} \\
\hline Labé & & & 1.73 & [0.76-3.95] & 1.69 & {$[0.75-3.80]$} \\
\hline Mamou & & & $2.34^{\star}$ & {$[1.01-5.40]$} & $2.27^{\star}$ & {$[1.00-5.94]$} \\
\hline Nzérékoré & & & 1.91 & {$[0.76-4.77]$} & 1.88 & {$[0.76-4.61]$} \\
\hline \multicolumn{7}{|l|}{ Place of delivery } \\
\hline Home & & & 1 & & 1 & \\
\hline Health facility & & & $1.90^{\star \star \star}$ & [1.32-2.74] & $1.94^{\star \star \star}$ & [1.34-2.80] \\
\hline \multicolumn{7}{|l|}{ Religion } \\
\hline Muslim & & & 1 & & 1 & \\
\hline Christian & & & 1.60 & [0.74-3.48] & 1.60 & {$[0.74-3.46]$} \\
\hline \multicolumn{7}{|l|}{ Type of Household } \\
\hline Monogame & & & 1 & & & \\
\hline Polygamous & & & $0.68^{\star}$ & {$[0.47-0.98]$} & $0.68^{*}$ & {$[0.48-0.98]$} \\
\hline \multicolumn{7}{|l|}{ Woman currently working } \\
\hline No & & & 1 & & & \\
\hline Yes & & & 1.21 & [0.84-1.74] & 1.21 & {$[0.84-1.74]$} \\
\hline \multicolumn{7}{|l|}{ Random effects } \\
\hline Community characteristic & & & & & & \\
\hline
\end{tabular}


Note : ${ }^{\star} p<0.05 ;{ }^{* \star} p<0.01{ }^{* \star \star} p<0.001$

\section{Discussion}

The purpose of this work was to determine the individual and contextual factors of the practice of exclusive breastfeeding in Guinea.

\section{Prevalence}

The practice of exclusive breastfeeding in Guinea remains low compared to that desired by the WHO which is $50 \%$ by 2025 . This low prevalence of Exclusive breastfeeding in Guinea could be explained on the one hand by the low attendance of health facilities for childbirth which is an opportune time to bring mothers to adhere to this practice. On the other hand by the weak implication of the spouse and the family members to support the breastfeeding woman. However, the increase in this rate calls for the setting up of campaigns to promote exclusive breastfeeding towards women, including mothers-in-law as well as sisters-in-law, the husband in order to target all those who have an influence on the infant's food choice. This would allow mothers to adapt a safe and optimal feeding method for their infants, but also to avoid being influenced by incorrect and erroneous information from family members and also from the community.

This prevalence is lower than those reported respectively in Tanzania 41\%, and in Ethiopia 49\% [21, 22].

\section{Associated factors}

In this study, the age of breastfeeding, the place of delivery, the region of residence and the type of household were statistically associated with the practice of exclusive breastfeeding. This study found that the child's age was statistically associated with the practice of exclusive breastfeeding. Our results show that the practice of El decreased significantly from the age of 2 months to 5 months. This correlation between age and exclusive breastfeeding could be explained by the fact that as the child's age increases, mothers are more likely to start introducing other foods. Indeed, they perceive that breast milk alone may not be enough to meet the nutritional needs of the child. Several studies reinforce the existing correlation between the practice of El by a mother and the age of the child like: Those reported in certain countries of West Africa [23-25]. These results suggest a crucial implication of health professionals, paying more attention to breastfeeding mothers by giving them advice to only breastfeed the child without associating it with anything other than medication. They should also help mothers overcome all the obstacles unfavorable to the practice of exclusive breastfeeding through awareness sessions (forum, picture box) including the involvement of the media. 
This study found that the region of residence was significantly associated with the practice of exclusive breastfeeding. Women in the Faranah and Mamou administrative regions were more likely to exclusively breastfeed compared to those living in Conakry. Our results could be explained by the fact that these women do not have easy access to breast milk substitutes given the high cost; this makes them give their breasts to the baby during the first 6 months of life. Another argument is that, they do not fully follow the evolution of new technology, which means that they may not adhere to breast milk substitutes. Unlike the women of Conakry, who are much more exposed to activities in the tertiary sector requiring the separation of mother and child for a long time. With the emergence of new technology and culture shock, the women of Conakry do not want to lose their physical form while breastfeeding. They have greater access to breast milk substitutes. Our results are contrary to those reported by Anthony et al. or mothers who resided in the Volta region were more likely to practice exclusive breastfeeding than mothers in other regions of Ghana who they attributed to the attachment of women to cultural beliefs. [26]

In this study, women who gave birth in a health facility were more likely to practice exclusive breastfeeding than those who gave birth at home. This could be explained in our study by the involvement of health professionals in raising the awareness of women on the exclusive breastfeeding component during the various pre and postnatal contacts that make ideal times to encourage mothers to adhere to this practice. It is appropriate that the government put in place other strategies in addition to the involvement of health professionals but also broaden that focused on the community. Thus, all community strategies to promote exclusive breastfeeding should no longer target only breastfeeding women but also those who influence behavior, such as village birth attendants, mothers-in-law and even women who are not breastfeeding. Our results are similar to those found by Tampah-Naah et al. in Ghana, Nkala et al. in Tanzania, and Bethlihem Adugna et al., in Ethiopia [21, 27, 28].

The study found that women living in polygamous households had a reduced chance of exclusive breastfeeding. These results could be attributed to the fact that in polygamous households, unlike monogamous households, women are more active in their daily research, for the reason that men are unable to meet the needs of these women. in entirety. Also, out of ignorance, the woman gives other milk to her child so that the child has a good build so that he can be loved in the family which is an honor for the mother. She states that breast milk substitutes are richer than that from her breast, which is not true. Another explanation is that in polygamous homes unlike monogamous homes in place and place of real love and dialogue it is the order, the strength and the cycle of turn in humans which are compulsory, all of which is overseen by a jealousy not to let another benefit for a long time to benefit from the intimacy of the husband in his place, although she is a nurse; So you have to limit breastfeeding time and use the teat. This can also be attributed to aesthetic reasons, the woman always wants to keep her initial shape, while when the child breastfeeds a lot it causes the breasts to fall, however, one of the factors that attracts the man is the position of the breast.

The results we have achieved are nationally representative. Our study could contribute to a better understanding of the factors associated with the practice of exclusive breastfeeding in Guinea. Also, it 
will also contribute to strengthening the implementation of promising strategies for possible improvement of this practice in Guinea.

\section{Conclusion}

This study shows that the prevalence of exclusive breastfeeding remains low in Guinea with 33\% compared to the recommendations of the World Health Organization which is $50 \%$ by 2025 . The main predictors of exclusive breastfeeding in our study were: the breastfeeding age of the child, the region of residence, the place of delivery and the type of household. To increase this prevalence, it would be necessary for the government to take into account the main associated factors in strategies for promoting exclusive breastfeeding.

\section{Declaration}

\section{Ethics approval and consent to participate}

The study protocol was submitted to and approved by the National Health Research Ethics Committee of Burkina Faso. The National Institute of Statistics of Guinea facilitated the obtaining of the databases for the secondary analysis.

\section{Consent for publication}

Not applicable.

\section{Availability of data and materials}

The data from the Guinea Demographic and Health Survey (DHS) generated and/or analyzed during the current study are available and accessible on the DHS program website (http://dhsprogram.com ).

\section{Competing interests}

The authors declare that they have no competing interests.

\section{Funding}

This study benefited from the financial support of the Guinean government in the collection of data through the National Institute of Statistics.

\section{Authors' contributions}

Anne Marie Soumah led the conception and design of the study, analysis and interpretation of the data, and drafting of the article. 
Mamadou Diouldé Baldé participated in the conception and design of the study, analysis and interpretation of the data, and revision of the article.

Mahamadi Tassembedo participated in the conception and design of the study, analysis and interpretation of the data, and revision of the article.

Ousmane Ouédraogo participated in the conception and design of the study, analysis and interpretation of the data, and revision of the article.

Franck Garanet participated in the conception and design of the study, analysis and interpretation of the data, and revision of the article.

Adja Mariam Ouédraogo participated in analysis and interpretation of the data and revision of the Article

Aminata Yara participated in analysis and interpretation of the data and revision of the Article

Mamady Koulibaly participated in analysis and interpretation of the data and revision of the Article

Ibrahima Camara participated in analysis and interpretation of the data and revision of the Article

Seni Kouanda participated in the conception and design of the study, analysis and interpretation of the data, and revision of the article. All authors contributed to the development, review, and approval of the final manuscript

\section{Acknowledgements}

The authors are grateful for the support of the National Institute of Statistics of Guinea in obtaining the database and for their valuable contributions to the preparation of this paper.

\section{References}

1. Communication UD of. Tracking progress on child and maternal nutrition: a survival and development priority. Unicef; 2009.

2. Institut National de la Statistique Ministère du Plan et du Développement Economique. Enquête Démographique et de Santé et à Indicateurs Multiplies (EDS V). Guinée, Conakry. Juillet 2019.

3. Direction Nationale de la Santé Familiale et de la Nutrition, Division Alimentation et Nutrition, Ministère de la santé publique. Enquête nationale nutrition-santé, basée sur la méthodologie SMART, 2015

4. Organisation Mondiale de la Santé. Plan d'application exhaustif concernant la nutrition chez la mère, le nourrisson et le jeune enfant. 2014; In: Plan d'application exhaustif concernant la nutrition chez la mère, le nourrisson et le jeune enfant 2014. 
5. Scaling Up Nutrition (SUN). Scaling up nutrition: a framework for action. Washington, DC: UNSCN, 2010

6. Bhutta ZA, Das JK, Rizvi A, et al, The Lancet Nutrition Interventions Review Group, and the Maternal and Child Nutrition Study Group. Evidence based interventions for improvement of maternal and child nutrition: what can be done and at what cost? Lancet 2013

7. Agho KE, Dibley MJ, Odiase JI, Ogbonmwan SM. Determinants of exclusive breastfeeding in Nigeria. BMC Pregnancy Childbirth. 2011;11(1):2.

8. Mullany LC, Katz J, Li YM, Khatry SK, LeClerq SC, Darmstadt GL, et al. Breastfeeding patterns,time to initiation, and mortality risk among newborns in southern Nepal. J Nutr. 2008;138(3):599-603.

9. Edmond KM, Kirkwood BR, Amenga-Etego S, Owusu-Agyei S, Hurt LS. Effect of early infant feeding practices on infection-specific neonatal mortality: an investigation of the causal links with observational data from rural Ghana. Am J Clin Nutr.2007;86(4):1126-1131.

10. Turck $D$, Pédiatrie $C$ de $N$ de la SF de. Allaitement maternel: les bénéfices pour la santé de l'enfant et de sa mère. Arch Pédiatrie. 2005;12:S145-S165.

11. Gartner LM, Morton J, Lawrence RA, Naylor AJ, O'Hare D, Schanler RJ, et al.Breastfeeding and the use of human milk. Pediatrics. 2005;115(2):496-506.

12. Chantry AA, Monier I, Marcellin L. Allaitement maternel (partie 1): fréquence, bénéfices et inconvénients, durée optimale et facteurs influençant son initiation et son prolongetion. Recommandations pour la pratique clinique. J Gynécologie Obstétrique Biol Reprod. 2015;44(10):1071-1079.

13. Sage L. Connaissances sur l'allaitement maternel des femmes allaitantes avant leur sortie de maternité au CHU Estaing de Clermont-Ferrand. Citeseer; 2014.

14. Victora C.G., Horta B.L., de Mola C.L., Quevedo L., Pinheiro R.T., Gigante D.P., Gonçalves H., Barros F.C. Association between breastfeeding and intelligence, educational attainment, and income at 30 years of age: A prospective birth cohort study from Brazil. Lancet Glob. Health. 2015;3:e199-e205. doi: 10.1016/S2214-109X(15)70002-1

15. Mohamed MJ, Ochola S, Owino VO. Comparison of knowledge, attitudes and practices on exclusive breastfeeding between primiparous and multiparous mothers attending Wajir District hospital, Wajir County, Kenya: a cross-sectional analytical study. Int Breastfeed J [Internet].2018 Mar 2;13.

16. Ogbo FA, Eastwood J, Page A, Efe-Aluta O, Anago-Amanze C, Kadiri EA, et al. The impact of sociodemographic and health-service factors on breast-feeding in sub-Saharan African countries with high diarrhoea mortality. Public Health Nutr. 2017;20(17):3109-3119.

17. Jones G, Steketee RW, Black RE, Bhutta ZA, Morris SS, Group BCSS. How many child deaths can we prevent this year? The lancet. 2003;362(9377):65-71. 
18. Melissa F. Young, Phuong Nguyen, Shivani Kachwaha, Lan Tran Mai, Sebanti Ghosh, Rajeev Agrawal, Jessica Escobar-Alegria, Purnima Menon, Rasmi Avula. It takes a village: An empirical analysis of how husbands, mothers-in-law, health workers, and mothers influence breastfeeding practices in Uttar Pradesh, India. Maternal and Child Nutrition,First published :26 November 2019

19. Onah S, Osuorah DIC, Ebenebe J, Ezechukwu C, Ekwochi U, Ndukwu I. Infant feeding practices and maternal socio-demographic factors that influence practice of exclusive breastfeeding among mothers in Nnewi South-East Nigeria: a cross-sectional and analytical study. Int Breastfeed J. 2014 May 20;9(1):6.

20. Egata G, Berhane Y, Worku A. Predictors of non-exclusive breastfeeding at 6 months among rural mothers in east Ethiopia: a community-based analytical cross-sectional study. Int Breastfeed J. 2013;8(1):8.

21. Nkala TE, Msuya SE. Prevalence and predictors of exclusive breastfeeding among women in Kigoma region, Western Tanzania: a community based cross-sectional study. Int Breastfeed J. 2011;6(1):17.

22. Alemayehu T, Haidar J, Habte D. Determinants of exclusive breastfeeding practices in Ethiopia. Ethiop J Health Dev [Internet]. 2009 Aug 3; 23(1).

23. Onah S, Osuorah DIC, Ebenebe J, Ezechukwu C, Ekwochi U, Ndukwu I. Infant feeding practices and maternal socio-demographic factors that influence practice of exclusive breastfeeding among mothers in Nnewi South-East Nigeria: a cross-sectional and analytical study. Int Breastfeed J. 2014;9(1):6.

24. Mogre V, Dery M, Gaa PK. Knowledge, attitudes and determinants of exclusive breastfeeding practice among Ghanaian rural lactating mothers. Int Breastfeed J. 2016;11(1):12.

25. Gusmão AM, Béria JU, Gigante LP, Leal AF, Schermann LB. The prevalence of exclusive breastfeeding and associated factors: a cross-sectional study of teenage mothers between 14 and 16 years of age in the city of Porto Alegre in the State of Rio Grande do Sul, Brazil. Cienc Saude Coletiva. 2013 Nov;18(11):3357-68.

26. Anthony Mwinilanaa Tampah-Naah and Akwasi Kumi-Kyereme. Determinants of exclusive breastfeeding among mothers in Ghana: a cross-sectional study. Int Breastfeed J.14 oct.2013

27. Tampah-Naah AM, Kumi-Kyereme A. Determinants of exclusive breastfeeding among mothers in Ghana: a cross-sectional study. Int Breastfeed J. 2013 Oct 14;8(1):13.

28. Adugna B, Tadele H, Reta F and Berhan $\mathrm{Y}$. Determinants of exclusive breastfeeding in infants less than six months of age in Hawassa, an urban setting, Ethiopia Int Breastfeed J.2017 2 nov; 12 : 45

\section{Figures}


Women with a child younger than

24 months of age and the child is

the latest born $n=3036$

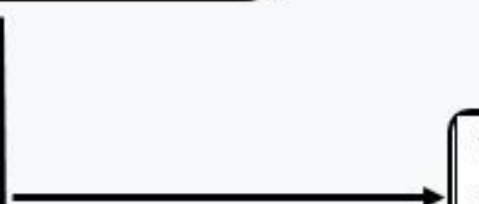

Women whose last child under 24

months of age has died $n=174$

Women with a living child under

24 months of age who was last

horn $n=286$ ?

Women not living with their child under 24 months of age $n=71$

Women living with their child

under 24 months of age $n=2791$

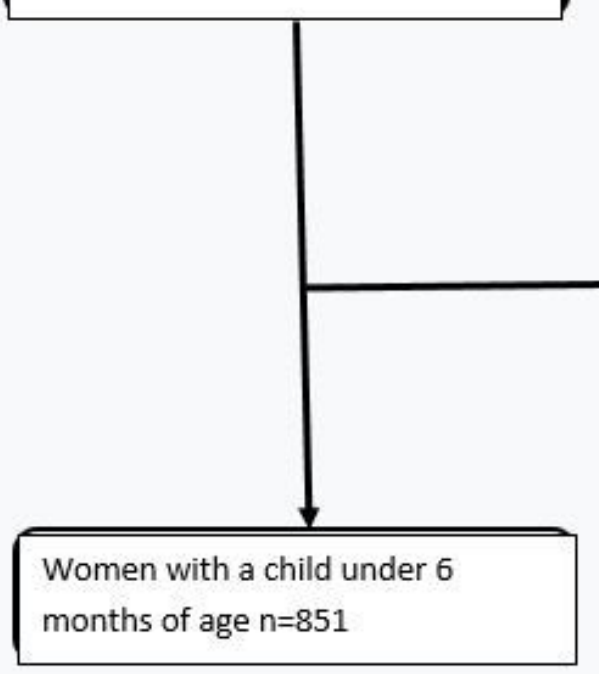

Women with a child over 6 months

of age $n=1940$

\section{Figure 1}

The flow chart for study participants 